\title{
Concentrations of Antidepressants, Antipsychotics, and Benzodiazepines in Hair Samples from Postmortem Cases
}

\author{
Maximilian Methling ${ }^{1,2}$ (D) . Franziska Krumbiegel ${ }^{1} \cdot$ Ayesha Alameri $^{1} \cdot$ Sven Hartwig ${ }^{1} \cdot$ Maria K. Parr $^{2}$. \\ Michael Tsokos ${ }^{1}$
}

Accepted: 30 January 2020 / Published online: 10 February 2020

(C) The Author(s) 2020

\begin{abstract}
Certain postmortem case constellations require intensive investigation of the pattern of drug use over a long period before death. Hair analysis of illicit drugs has been investigated intensively over past decades, but there is a lack of comprehensive data on hair concentrations for antidepressants, antipsychotics, and benzodiazepines. This study aimed to obtain data for these substances. A LC-MS/MS method was developed and validated for detection of 52 antidepressants, antipsychotics, benzodiazepines, and metabolites in hair. Hair samples from 442 postmortem cases at the Institute of Legal Medicine of the Charité-University Medicine Berlin were analyzed. Postmortem hair concentrations of 49 analytes were obtained in 420 of the cases. Hair sample segmentation was possible in 258 cases, and the segments were compared to see if the concentrations decreased or increased. Descriptive statistical data are presented for the segmented and non-segmented cases combined $(n=420)$ and only the segmented cases $(n=258)$. An overview of published data for the target substances in hair is given. Metabolite/parent drug ratios were investigated for 10 metabolite/parent drug pairs. Cases were identified that had positive findings in hair, blood, urine, and organ tissue. The comprehensive data on postmortem hair concentrations for antidepressants, antipsychotics, and benzodiazepines may help other investigators in their casework. Postmortem hair analysis results provide valuable information on the drug intake history before death. Pattern changes can indicate if drug intake stopped or increased before death. Results should be interpreted carefully and preferably include segmental analysis and metabolite/parent drug ratios to exclude possible contamination.
\end{abstract}

Keywords Hair analysis $\cdot$ Postmortem hair concentration $\cdot$ Antidepressant $\cdot$ Antipsychotic $\cdot$ Toxicology

Key Points 1. A sensitive and robust LC-MS/MS method for the detection of antidepressants, antipsychotics, and benzodiazepines in hair was developed, validated, and applied to 420 cases.

2. Comprehensive data on postmortem hair concentrations for 41 substances and their respective metabolites are given.

3. Metabolite/parent drug ratios provide valuable information for interpretation of postmortem hair concentrations.

4. Segmental hair analysis in postmortem toxicology can provide useful information on changes in the pattern of drug use.

5. An overview of quantitative data published in the literature for antidepressants, antipsychotics, and benzodiazepines in hair revealed a lack of comprehensive data.

This article is part of the Topical Collection on Medicine

Maximilian Methling

maximilian.methling@charite.de

1 Institute of Legal Medicine and Forensic Sciences, CharitéUniversity Medicine Berlin, Turmstrasse 21 Haus N, 10559 Berlin, Germany

2 Institute of Pharmacy, Pharmaceutical Chemistry, Freie Universität Berlin, Königin-Luise-Straße 2+4, 14195 Berlin, Germany

\section{Introduction}

The detection and quantification of drugs of abuse in hair has been the focus of research over the last three decades $[1,2]$. It is well-known that intra- and inter-individual differences, hair pigmentation [3], and hair cosmetics [4] have major impacts on the results of these analyses $[2,5]$. Therefore, such results are always interpreted with great care, and this can provide valuable retrospective insight into the pattern of consumption $[5,6]$. Currently, scientists can evaluate, to a certain degree, how often a person was exposed to or consumed a certain drug within recent months. This enables widespread application of hair analysis in postmortem toxicology [7, 8], workplace drug testing, and abstinence control programs [2, 9].

There has been extensive research on the detection of all kinds of drugs in hair, and the idea that hair concentrations could be correlated to the dose taken is of particular interest $[10,11]$. However, after initial research provided insight on inter-individual differences, research on substances other than 
drugs of abuse has decreased somewhat. Quantitative data from hair analyses for these substances are published in case reports $[12,13]$ or studies with only a small number of subjects [14-22]. There have been few comprehensive studies with large populations or investigations of a wide range of substances [23, 24].

Antidepressants and antipsychotics are commonly found in postmortem toxicology [25] because of their high prescription rates and relatively high toxicities in overdose situations. Because of the limited data for such substances, results from hair analyses in these cases are hard to interpret. Segmental analyses can help provide more information about changes in drug intake $[16,17,26]$, but more quantitative data from hair analyses is needed for comparison and interpretation. The aim of this research was to expand the knowledge base of concentrations of antidepressants, antipsychotics, and benzodiazepines in postmortem hair samples.

First, a LC-MS/MS method was developed and validated for the detection of 52 substances (antidepressants, antipsychotics, and benzodiazepines) according to the guidelines of the German Society of Forensic Toxicology (GTFCh) [27, 28]. Then, within an observational study, hair samples from 442 postmortem cases were analyzed with this method. Overall, quantitative data from 420 postmortem cases was obtained. Descriptive statistical data and the importance of careful interpretation of results from postmortem hair analyses are discussed.

\section{Material and Methods}

\section{Reagents and Chemicals}

Sample preparation was performed with analytical grade solvents obtained from Merck KGaA (Darmstadt, Germany). LC-MS grade acetonitrile for the mobile phase was obtained from Fisher Scientific GmbH (Schwerte, Germany), and water and formic acid (99\% purity) were purchased from Acros Organics (Geel, Belgium). The following deuterated standards (99\% purity) were purchased from LGC Standards $\mathrm{GmbH}$ (Wesel, Germany): 6-monoacetylmorphine- $d_{3}$, alphahydroxyalprazolam- $d_{5}$, alprazolam- $d_{5}, 7$ aminoflunitrazepam- $d_{7}$, amphetamine- $d_{5}$, benzoylecgonine$d_{5}$, buprenorphine- $d_{4}$, clonazepam- $d_{4}$, cocaine- $d_{3}$, cocaethylene- $d_{3}$, codeine- $d_{3}$, diazepam- $d_{5}$, dihydrocodeine$d_{3}$, 2-ethylidene-1,5-dimethyl-3,3-diphenylpyrrolidine- $d_{3}$, flunitrazepam- $d_{7}$, fentanyl- $d_{5}$, ketamine- $d_{4}$, lorazepam- $d_{4}$, methamphetamine- $d_{5}, 3,4$-methylenedioxyamphetamine- $d_{5}$, 3,4-methylenedioxy- $N$-ethylamphetamine- $d_{6}, 3,4$ methylenedioxy- $N$-methylamphetamine- $d_{5}$, methadone- $d_{9}$, methylecgonine- $d_{3}$, morphine- $d_{3}$, nordazepam- $d_{5}$, norbuprenorphine- $d_{3}$, norcocaine- $d_{3}$, nortilidine- $d_{3}$, oxazepam- $d_{5}$, oxycodone- $d_{3}$, tilidine- $d_{6}$, temazepam- $d_{5}$, and tramadol- $d_{3}$. A standard mixture containing $1 \mathrm{ng} / \mu \mathrm{L}$ of each internal standard in methanol was prepared and added to each hair sample.

Furthermore, the following standards ( $99 \%$ purity) were purchased from LGC Standards GmbH (Wesel, Germany) or Sigma Aldrich (St. Louis, MO): 7-aminoflunitrazepam, alprazolam, amisulpride, amitriptyline, aripiprazole, benperidol, bromazepam, bupropion, chlorpromazine, chlorprothixene, citalopram, clomipramine, clonazepam, clozapine, diazepam, doxepin, flunitrazepam, fluoxetine, fluphenazine, flupentixol, fluvoxamine, haloperidol, hydroxyrisperidone, levomepromazine, maprotiline, melperone, methylphenidate, mianserin, midazolam, mirtazapine, norcitalopram, norclomipramine, norclozapine, nordiazepam, nordoxepin, nortriptyline, norvenlafaxine, olanzapine, opipramol, oxazepam, paroxetine, pipamperone, promethazine, quetiapine, sulpiride, temazepam, trazodone, trimipramine, venlafaxine, and zuclopenthixol. A standard mixture containing $10 \mathrm{ng} / \mu \mathrm{L}$ of each analyte in methanol was prepared and diluted as required.

\section{Instruments and Software}

The samples were analyzed on a LC-MS system (LC infinity 1290 with binary pump and degasser, 6460 Triple Quadrupole MS; Agilent Technologies Deutschland GmbH, Waldbronn, Germany) and separated by a Kinetex ${ }^{\circledR} \mathrm{C} 18$ column $(150 \times$ $2.1 \mathrm{~mm}$ i.d., $1.7 \mu \mathrm{m}$, Phenomenex, Torrance, California,USA). Dynamic multiple reaction monitoring (MRM) and an Agilent Jet Stream electrospray-ionization source were used for the data acquisition in positive ionization mode. The data acquisition was performed with MassHunter Workstation Software version B.06.00, and MassHunter Quantitative Analysis B.06.00 (Agilent Technologies Deutschland $\mathrm{GmbH}$ ) was used for quantification. Valistat 2.0 was used to perform statistical tests during method validation. OriginPro software (OriginLab Corp., Northampton, Massachusetts, USA) was used to calculate the descriptive statistics and to create all the figures.

\section{Hair Sample Preparation}

Hair sample preparation followed a previously described method [29] that is routinely used in the laboratory. Hair samples in the observational study were segmented into lengths of 0-2 cm [S1] and 2-4 cm [S2] measured from the proximal (scalp) end. A full length of $4 \mathrm{~cm}$ was used in cases where the proximal end of the hair sample was not obvious. Lengths shorter than $4 \mathrm{~cm}$ were also segmented if possible.

\section{Selection of Analytes}

The annual report [30] on the prescription rates of drugs in Germany lists several substance classes in the chapter for psychotropic drugs, including benzodiazepines, antidepressants, 
antipsychotics, and stimulants. From that list, the substances shown in Table 1 were selected as analytes of interest. In contrast to other regions, for example, the USA, all these substances were marketed and prescribed in Germany in 2015.

\section{Characteristics of Chromatography, Internal Standards, Transitions, and Retention Times}

The MRM mass transitions were manually optimized for each substance. Next, the mobile phase gradient was optimized with regard to acceptable separation of the target from matrix components. Table 2 summarizes the main MRM transitions, retention time, and corresponding internal standard for each substance. A mixture of water containing $0.1 \%$ formic acid (eluent $\mathrm{A}$ ) and acetonitrile (eluent B) was used as the mobile phase for gradient elution over $18 \mathrm{~min}$ as follows: start, $7 \% \mathrm{~B}$; 0-8 $\mathrm{min}, 30 \% \mathrm{~B}$; 8-14 $\mathrm{min}, 35 \% \mathrm{~B}$; $14-16 \mathrm{~min}, 40 \% \mathrm{~B}$; and 16-17 $\mathrm{min}, 7 \% \mathrm{~B}$ (starting condition). The flow rate was set to $0.4 \mathrm{~mL} / \mathrm{min}$, and the injection volume was $5 \mu \mathrm{L}$. The column temperature was $40{ }^{\circ} \mathrm{C}$. In addition, the source parameters were optimized to the following settings: drying gas at $250{ }^{\circ} \mathrm{C}$ with a flow rate of $10 \mathrm{~L} / \mathrm{min}$, sheath gas at $380{ }^{\circ} \mathrm{C}$ with a flow rate of $12 \mathrm{~mL} / \mathrm{min}$, nebulizer pressure of $25 \mathrm{psi}$, and capillary voltage of $4500 \mathrm{~V}$. A dynamic detection mode (dynamic MRM) was used to increase the sensitivity, reproducibility, and precision of the 247 mass transitions. Because the minimum cycle time was $432.0 \mathrm{~ms}$ with a maximum of 32 concurrent transitions, the cycle time was set at $500 \mathrm{~ms}$, resulting in a minimum dwell time of $12.13 \mathrm{~ms}$.

\section{Method Validation}

The method validation followed the protocol in the guidelines of the GTFCh [27, 28]. Six different blank hair specimens with and without the internal standard were first tested to prove the selectivity of the method. Then, a calibration range between 0.005 and $2.5 \mathrm{ng} / \mathrm{mg}$ was tested with spiked blank hair samples that were injected six times. Next, the limit of detection and lower limit of quantification (LLOQ) were estimated following the protocol of the German standard DIN 32645 [31]. The accuracy was tested with hair samples spiked at a low concentration $(0.03 \mathrm{ng} / \mathrm{mg})$ and a high concentration $(1 \mathrm{ng} / \mathrm{mg})$ over 5 days. The same concentration levels were prepared to assess the stability of analytes in processed samples that were stored in the autosampler for $77 \mathrm{~h}$. Furthermore, five different hair specimens were spiked at the same concentration levels before extraction and after extraction to test matrix effects and the recovery.

\section{Observational Study of Postmortem Cases}

\section{Case Selection}

The main aim of this study was to obtain comprehensive data on a wide range of psychoactive drugs. Effective preselection of cases was important to detect as many positive cases as possible. As a starting point, postmortem cases from 2012 to 2015 with positive results for antidepressants and antipsychotics in blood, urine, or organ tissue were identified [25]

Table 1 Analytes of interest from the annual drug prescription report [30]

\begin{tabular}{|c|c|c|c|c|c|c|}
\hline $\begin{array}{l}\text { Tricyclic } \\
\text { antidepressants }\end{array}$ & $\begin{array}{l}\text { Tetracyclic } \\
\text { antidepressants }\end{array}$ & $\begin{array}{l}\text { Selective serotonin } \\
\text { inhibitors }\end{array}$ & $\begin{array}{l}\text { Other } \\
\text { substances }\end{array}$ & $\begin{array}{l}\text { Typical } \\
\text { neuroleptics }\end{array}$ & $\begin{array}{l}\text { Atypical } \\
\text { neuroleptics }\end{array}$ & Benzodiazepines \\
\hline Amitriptyline & Maprotiline & Citalopram & Venlafaxine & Chlorprothixene & Amisulpride & Diazepam \\
\hline Nortriptyline & Mirtazapine & $N$-Desmethylcitalopram & $\begin{array}{l}O \text {-Desmethyl } \\
\text { venlafaxine }\end{array}$ & Flupentixol & Clozapine & $\begin{array}{l}\text { Nordazepam } \\
\text { (Desmethyldiazepam) }\end{array}$ \\
\hline Clomipramine & Mianserin & Fluoxetine & Bupropion & Haloperidol & $N$-Desmethylclozapine & Flunitrazepam \\
\hline $\begin{array}{l}N \text {-Desmethyl } \\
\text { clomipramine }\end{array}$ & Paroxetine & Methylphenidate & Promethazine & Olanzapine & 7-Aminoflunitrazepam & \\
\hline Doxepin & & Sertraline & Ritalinic acid & Zuclopenthixol & Quetiapine & Alprazolam \\
\hline $\begin{array}{l}N \text {-Desmethyl } \\
\text { doxepin }\end{array}$ & Fluvoxamine & Trazodone & Chlorpromazine & Risperidone & Temazepam & \\
\hline Opipramol & & & & Pipamperone & $\begin{array}{l}\text { Paliperidone } \\
\quad(9- \\
-- \\
\text { hydroxyrisperidone) }\end{array}$ & Midazolam \\
\hline \multirow[t]{5}{*}{ Trimipramine } & & & Benperidol & Aripiprazole & Clonazepam & \\
\hline & & & & Levomepromazine & & Oxazepam \\
\hline & & & & Sulpiride & & \\
\hline & & & & Fluphenazine & & \\
\hline & & & & & & \\
\hline
\end{tabular}


Table 2 MRM transitions, internal standards, and retention times for all analytes

\begin{tabular}{|c|c|c|c|c|}
\hline Target substances & Target MRM transitions & Qualifier MRM transitions & Internal standards & Retention times \\
\hline \multicolumn{5}{|l|}{ Tricyclic antidepressants } \\
\hline Amitriptyline & $278.1->233.1$ & $278.1 \rightarrow 105.1$ & Alprazolam- $d_{5}$ & 11.8 \\
\hline Nortriptyline & $264.1->117.0$ & $264.1->233.1$ & Desmethyldiazepam- $d_{5}$ & 11.4 \\
\hline Clomipramine & $315.1->58.1$ & $315.1->86.1$ & Diazepam- $d_{5}$ & 14.2 \\
\hline$N$-Desmethylclomipramine & $301.1 \rightarrow 72.1$ & $301.1 \rightarrow 44.1$ & Temazepam- $d_{5}$ & 13.6 \\
\hline Doxepin & $280.2->77.1$ & $280.2->107.1$ & Fentanyl- $d_{5}$ & 9.4 \\
\hline$N$-Desmethyldoxepin & $266.1->79.1$ & $266.1->235.1$ & Desmethyldiazepam- $d_{5}$ & 9.2 \\
\hline Opipramol & $364.5->171.2$ & $364.5->143.1$ & Cocaethylene- $d_{3}$ & 8.3 \\
\hline Trimipramine & $295.2->58.1$ & $295.2->100.1$ & Methadone- $d_{9}$ & 12.4 \\
\hline \multicolumn{5}{|l|}{ Tetracyclic antidepressants } \\
\hline Maprotiline & $278.1->250.2$ & $278.1->219.1$ & Clonazepam- $d_{4}$ & 11.6 \\
\hline Mirtazapine & $266.2->195.1$ & $266.2->209.1$ & Ketamine- $d_{4}$ & 4.82 \\
\hline Mianserin & $265.1->208.1$ & $265.1 \rightarrow 91.1$ & Fentanyl- $d_{5}$ & 9.00 \\
\hline \multicolumn{5}{|l|}{ Selective serotonin inhibitors } \\
\hline Citalopram & $325.2->109.0$ & $325.2->234.1$ & Fentanyl- $d_{5}$ & 9.40 \\
\hline$N$-Desmethylcitalopram & $311.2->293.1$ & $311.2->262.1$ & Fentanyl- $d_{5}$ & 9.10 \\
\hline Fluoxetine & $310.1->148.0$ & $310.1->44.1$ & Methadone- $d_{9}$ & 12.8 \\
\hline Paroxetine & $330.1->44.1$ & $330.1->192.1$ & Nitrazepam- $d_{5}$ & 10.6 \\
\hline Sertraline & $308.0->160.9$ & $308.0 \rightarrow 158.8$ & Temazepam- $d_{5}$ & 13.2 \\
\hline Fluvoxamine & $319.1->200.1$ & $319.1->258.0$ & Desmethyldiazepam- $d_{5}$ & 11.2 \\
\hline \multicolumn{5}{|l|}{ Other substances } \\
\hline Venlafaxine & $278.2 \longrightarrow 260.2$ & $278.2->215.1$ & Norcocaine- $d_{3}$ & 7.20 \\
\hline$O$-Desmethylvenlafaxine & $264.2->246.2$ & $264.2->107.1$ & 7-Aminoclonazepam- $d_{4}$ & 4.60 \\
\hline Bupropion & $240.1->130.9$ & $240.1->184.0$ & Tilidine- $d_{6}$ & 6.80 \\
\hline Methylphenidate & $234.1->56.1$ & $234.1->174.1$ & Tramadol- $d_{3}$ & 5.50 \\
\hline Ritalinic acid & $220.1->174.1$ & $220.1->84.1$ & MDE-D 6 & 4.20 \\
\hline Trazodone & $372.2->78.1$ & $372.2->148.1$ & Cocaethylene- $d_{3}$ & 7.70 \\
\hline \multicolumn{5}{|l|}{ Typical neuroleptics } \\
\hline Chlorprothixene & $316.1->84.1$ & $316.1->221.1$ & Diazepam- $d_{5}$ & 13.8 \\
\hline Flupentixol & $435.2->305.1$ & $435.2->100.1$ & Diazepam- $d_{5}$ & 15.1 \\
\hline Haloperidol & $376.1 \rightarrow 165.0$ & $376.1 \rightarrow 123.0$ & EDDP- $d_{3}$ & 10.0 \\
\hline Promethazine & $285.1 \rightarrow 198.0$ & $285.1 \rightarrow 86.1$ & EDDP- $d_{3}$ & 10.0 \\
\hline Zuclopenthixol & $401.1->97.1$ & $401.1 \rightarrow 100.1$ & Methadone- $d_{9}$ & 12.6 \\
\hline Chlorpromazine & $319.1->58.1$ & $319.1->86.1$ & Methadone- $d_{9}$ & 13.2 \\
\hline Pipamperone & $376.2->165.1$ & $376.2->291.1$ & MDMA- $d_{5}$ & 3.70 \\
\hline Benperidol & $382.2->123.0$ & $382.2->165.1$ & Fentanyl- $d_{5}$ & 8.20 \\
\hline Levomepromazine & $329.2->58.1$ & $329.2->242.1$ & Methadone- $d_{9}$ & 12.0 \\
\hline Sulpiride & $342.1 \rightarrow>112.0$ & $342.1 \rightarrow 214.0$ & Morphine- $d_{3}$ & 2.30 \\
\hline Fluphenazine & $438.1 \rightarrow>143.0$ & $438.1 \rightarrow>171.1$ & Diazepam- $d_{5}$ & 13.8 \\
\hline Melperone & $264.1 \rightarrow 123.0$ & $264.1 \rightarrow 165.0$ & Norbuprenorphine- $d_{3}$ & 7.00 \\
\hline \multicolumn{5}{|l|}{ Atypical neuroleptics } \\
\hline Amisulpride & $370.2->196.0$ & $370.2->242.1$ & Benzoylecgonine- $d_{3}$ & 4.20 \\
\hline Clozapine & $327.1->270.1$ & $327.1->192.1$ & Norbuprenorphine- $d_{3}$ & 7.30 \\
\hline$N$-Desmethylclozapine & $313.1->191.1$ & $313.1->270.0$ & $\mathrm{MDA}-d_{5}$ & 6.40 \\
\hline Olanzapine & $313.1->256.0$ & $313.1 \rightarrow 198.0$ & Dihydrocodeine- $d_{6}$ & 2.80 \\
\hline Quetiapine & $384.2->253.1$ & $384.2->221.0$ & Cocaethylene- $d_{3}$ & 8.20 \\
\hline Risperidone & $411.2->69.1$ & $411.2->191.1$ & Tilidine- $d_{6}$ & 6.90 \\
\hline Paliperidone (9-Hydroxyrisperidone) & $427.2->69.1$ & $427.2->207.1$ & Norcocaine- $d_{3}$ & 6.70 \\
\hline Aripiprazole & $448.2->285.1$ & $448.2->176.1$ & Methadone- $d_{9}$ & 12.2 \\
\hline \multicolumn{5}{|l|}{ Benzodiazepines } \\
\hline Diazepam & $285.1->257.1$ & $285.1->222.1$ & Diazepam- $d_{5}$ & 15.8 \\
\hline Nordazepam (Desmethyldiazepam) & $271.1->165.0$ & $271.1->208.1$ & Desmethyldiazepam- $d_{5}$ & 11.4 \\
\hline Flunitrazepam & $314.1->211.0$ & $314.1->239.1$ & Methadone- $d_{9}$ & 12.9 \\
\hline 7-Aminoflunitrazepam & $284.1->93.1$ & $284.1 \rightarrow 226.0$ & 7-Aminoflunitrazepam- $d_{7}$ & 5.40 \\
\hline Alprazolam & $309.1->281.0$ & $309.1->274.1$ & Alprazolam- $d_{5}$ & 12.0 \\
\hline Midazolam & $326.1->222.1$ & $326.1->182.1$ & Fentanyl- $d_{5}$ & 8.38 \\
\hline Clonazepam & $316.0 \rightarrow 214.0$ & $316.0->241.0$ & Clonazepam- $d_{4}$ & 11.7 \\
\hline Oxazepam & $287.0->241.0$ & $287.0->104.0$ & Oxazepam- $d_{5}$ & 11.2 \\
\hline Temazepam & $301.1->283.1$ & $301.1->255.1$ & Temazepam- $d_{5}$ & 13.3 \\
\hline
\end{tabular}

$M D E A$ 3,4-methylenedioxy- $N$-ethyl-amphetamine, EDDP 2-ethylidene-1,5-dimethyl-3,3-diphenylpyrrolidine, $M D M A$ 3,4methylenedioxymethamphetamine, $M D A$ 3,4-methylenedioxy-amphetamine 
in a retrospective cross-sectional study. Furthermore, cases with a mention of the substances of interest in the prosecutor's file were identified. Hair samples taken during autopsy were not available in all cases. In total, hair samples from 442 cases were prepared, segmented if possible, and analyzed with the validated method.

Aggressive hair treatment like bleaching, coloration, or dyeing is known to reduce the amount of a drug incorporated into hair [4]. In our study, there was no information available on hair cosmetics. Therefore, a bias might be created by including cosmetically treated hair samples. To reduce further bias from differences in hair growth, only cases where head hair was available were included.

\section{Results}

\section{Method Validation}

The method had sufficient selectivity and showed no interfering or co-eluting signals in the chromatogram. It was then successfully validated according to the described guidelines $[27,28]$ and fulfilled all requirements for selectivity, accuracy, stability, matrix effects, and recovery. Figure 1 summarizes the linear range, limit of detection, LLOQ, and accuracy data for each analyte. The LLOQ range was $1.2-37 \mathrm{pg} / \mathrm{mg}$ and showed the method had good sensitivity. Mandel's $F$-test for linearity and the Cochran test for homogeneity of variance were used to show the calibration curve was linear between 0.005 and $0.05-2.5 \mathrm{ng} / \mathrm{mg}$ for all analytes. In cases were homogeneity of variance was not achieved, a weighting factor was applied (Fig. 1). The linear correlation coefficient ranged from $R=0.9226$ to $R=0.9998$. The matrix effects were acceptable (75-125\%) for each analyte (Fig. 2), and the recovery acceptance criterion (recovery $>50 \%$ ) was fulfilled for each analyte (Fig. 2). Over $77 \mathrm{~h}$, a slight loss of the target analytes was observed, but the maximum loss of peak area was below $25 \%$. In addition, the method was accurate and precise and fulfilled the acceptance criteria for repeatability, intermediate precision, and bias (Fig. 3).

\section{Observational Study of Postmortem Cases}

\section{Concentrations Detected in Hair}

One or more substances were detected in 420 cases. Segmental analysis was possible in 258 of the positive cases. Segmentation was not possible in cases with shorter hair lengths or samples where the proximal end of the hair was not clear because of the condition of the sample, for example, in putrefied cases where the hair was extremely knotted. The cases with positive findings were split in two datasets: group 1, which included only the segmented cases; and group 2, which combined the segmented and nonsegmented cases. The detected concentrations in hair for all analytes and metabolite ratios are displayed in Table 3 (group 1: segmented cases only) and Table 4 (group 2: segmented and non-segmented cases combined). The concentrations of both segments were normalized to the mean value for the segmented cases. The detected concentrations showed wide variation, and the descriptive statistics are presented as percentiles with the median. A metabolite/ parent drug ratio was calculated if possible. Although the substances mianserin, clonazepam, and chlorpromazine were included in the LC-MS/MS method, they had no positive case in the observed population.

\section{Concentrations Detected at Time of Death and in Postmortem Hair}

Toxicological findings at the time of death were available for some cases because the case selection included a previous cross-sectional study that investigated the detection of antidepressants and antipsychotics in suicide and non-suicide cases [25]. Table 5 summarizes the number of cases in which a substance was detected in blood, urine, or organ tissue as well as in the analyzed hair sample.

\section{Segmental Analysis}

In 258 cases, segmental analysis was conducted using hair segments of $0-2 \mathrm{~cm}$ [S1] and 2-4 cm [S2] measured from the proximal end. The results for both segments were compared to identify changes in the pattern of drug use. Figure 4 shows the frequency of decreases and increases of the drug concentrations from [S2] to [S1].

\section{Cases with Bias from Contamination}

Contamination from body fluids can lead to artifacts in the analysis of postmortem hair samples [32]. Four cases with high drug levels in hair that possibly have such artifacts are discussed. The toxicological findings from the postmortem blood analyses and hair analyses are displayed in Table 6.

\section{Discussion}

\section{Concentrations Detected in Hair: Meaning and Considerations}

Because of the wide range of detected concentrations, the data were classified in percentiles. This approach addresses the variation in concentrations and helps with comparison of positive findings in routine work [6]. Because different hair 


\begin{tabular}{|c|c|c|c|c|c|}
\hline substance name & LOD $[\mathrm{ng} / \mathrm{mg}]$ & LOQ $[\mathrm{ng} / \mathrm{mg}]$ & $R$ & weighting factor & \\
\hline \multicolumn{6}{|l|}{ Tricyclic Antidepressants } \\
\hline Amitriptyline & 0.0032 & 0.0039 & 0.9996 & - & \multirow{2}{*}{\begin{tabular}{|l|} 
Amitriptyline \\
Nortriptyline \\
\end{tabular}} \\
\hline Nortriptyline & 0.0028 & 0.0031 & 0.9951 & - & \\
\hline Clomipramine & 0.0110 & 0.0230 & 0.9963 & $1 / x^{3}$ & \multirow{2}{*}{\begin{tabular}{|l|} 
Clomipramine \\
N-Desmethylclomipramine \\
\end{tabular}} \\
\hline N-Desmethylclomipramine & 0.0020 & 0.0040 & 0.9982 & $1 / x^{3}$ & \\
\hline Doxepin & 0.0080 & 0.0170 & 0.9973 & $1 / x^{3}$ & Doxepin \\
\hline $\mathrm{N}$-Desmethyldoxepin & 0.0011 & 0.0016 & 0.9928 & - & N-Desmethyldoxepin \\
\hline Opipramol & 0.0020 & 0.0040 & 0.9997 & $1 / x^{3}$ & Opipramol \\
\hline Trimipramine & 0.0070 & 0.0210 & 0.978 & $1 / x^{3}$ & Trimipramine \\
\hline \multicolumn{6}{|l|}{ Tetracyclic Antidepressants } \\
\hline Maprotiline & 0.0008 & 0.0034 & 0.9894 & $1 / x^{2}$ & Maprotiline \\
\hline Mirtazapine & 0.0014 & 0.0028 & 0.9968 & $1 / x^{3}$ & Mirtazapine \\
\hline Mianserin & 0.0090 & 0.0100 & 0.9992 & $1 / x^{3}$ & Mianserin \\
\hline \multicolumn{6}{|l|}{ Selective Serotonin Inhibitors } \\
\hline Citalopram & 0.0016 & 0.0029 & 0.9956 & $1 / x^{2}$ & Citalopram \\
\hline N-Desmethylcitalopram & 0.0004 & 0.0037 & 0.999 & $1 / x^{2}$ & N-Desmethylcitalopram \\
\hline Fluoxetine & 0.0190 & 0.0190 & 0.9918 & $1 / x^{3}$ & \begin{tabular}{|r|} 
Fluoxetine \\
\end{tabular} \\
\hline Paroxetine & 0.0020 & 0.0030 & 0.9992 & $1 / x^{3}$ & \multirow{2}{*}{\begin{tabular}{|l|} 
Paroxetine \\
Sertraline \\
\end{tabular}} \\
\hline Sertraline & 0.0017 & 0.0039 & 0.9226 & $1 / x^{3}$ & \\
\hline Fluvoxamine & 0.0060 & 0.0230 & 0.9915 & - & Fluvoxamine \\
\hline \multicolumn{6}{|l|}{ Other Substances } \\
\hline Venlafaxine & 0.0025 & 0.0034 & 0.9982 & $1 / x^{3}$ & Venlafaxine \\
\hline O-Desmethylvenlafaxine & 0.0010 & 0.0030 & 0.9953 & $1 / x^{3}$ & O-Desmethylvenlafaxine \\
\hline Bupropion & 0.0022 & 0.0029 & 0.9975 & $1 / x^{3}$ & Bupropion \\
\hline Methylphenidate & 0.0023 & 0.0037 & 0.9995 & $1 / x^{3}$ & Methylphenidate \\
\hline Ritalinic acid & 0.0014 & 0.0026 & 0.9992 & $1 / x^{3}$ & Ritalinic acid \\
\hline Trazodone & 0.0017 & 0.0018 & 0.9933 & $1 / x^{3}$ & Trazodone \\
\hline Typical Neuroleptics & & & & & \\
\hline Chlorprothixene & 0.0050 & 0.0110 & 0.9907 & - & Chlorprothixene \\
\hline Flupentixol & 0.0018 & 0.0034 & 0.9987 & - & Flupentixol \\
\hline Haloperidol & 0.0019 & 0.0020 & 0.9981 & $1 / x^{3}$ & Haloperidol \\
\hline Promethazine & 0.0021 & 0.0024 & 0.9989 & $1 / x^{3}$ & Promethazine \\
\hline Zuclopentixol & 0.0180 & 0.0370 & 0.9983 & - & Zuclopentixol \\
\hline Chlorpromazine & 0.0018 & 0.0041 & 0.9988 & $1 / x^{3}$ & Chlorpromazine \\
\hline Pipamperone & 0.0013 & 0.0040 & 0.9956 & $1 / x^{3}$ & Pipamperone \\
\hline Benperidol & 0.0010 & 0.0030 & 0.9979 & $1 / x^{3}$ & Benperidol \\
\hline Levomepromazine & 0.0140 & 0.0200 & 0.9972 & - & Levomepromazine \\
\hline Sulpiride & 0.0007 & 0.0016 & 0.9979 & $1 / x^{3}$ & Sulpiride \\
\hline Fluphenazine & 0.0039 & 0.0045 & 0.9962 & - & Fluphenazine \\
\hline Melperone & 0.0012 & 0.0027 & 0.9986 & $1 / x^{3}$ & $\sqrt{\text { Melperone }}$ \\
\hline Atypical Neuroleptics & & & & & \\
\hline Amisulpride & 0.0006 & 0.0016 & 0.9949 & $1 / x^{3}$ & Amisulpride \\
\hline Clozapine & 0.0008 & 0.0029 & 0.9888 & $1 / x^{3}$ & Clozapine \\
\hline$N$-Desmethylclozapine & 0.0020 & 0.0023 & 0.9932 & - & N-Desmethylclozapine \\
\hline Olanzapin & 0.0022 & 0.0028 & 0.9997 & $1 / x^{3}$ & Olanzapin \\
\hline Quetiapine & 0.0020 & 0.0034 & 0.9992 & - & Quetiapine \\
\hline Risperidone & 0.0010 & 0.0040 & 0.9971 & $1 / x^{3}$ & Risperidone \\
\hline Paliperidone (9-Hydroxy-risperidone) & 0.0013 & 0.0014 & 0.9957 & $1 / x^{2}$ & Paliperidone (9-Hydroxy-risperidone) \\
\hline Aripiprazole & 0.0130 & 0.0190 & 0.9954 & - & \begin{tabular}{|l|l|} 
Aripiprazole \\
\end{tabular} \\
\hline Benzodiazepine group & & & & & \\
\hline Diazepam & 0.0012 & 0.0029 & 0.9998 & $1 / x^{3}$ & Diazepam \\
\hline Nordazepam(Desmethyldiazepam) & 0.0160 & 0.0230 & 0.9913 & - & Nordazepam(Desmethyldiazepam) \\
\hline Flunitrazepam & 0.0100 & 0.0210 & 0.9984 & - & Flunitrazepam \\
\hline 7-Aminoflunitrazepam & 0.0130 & 0.0180 & 0.9909 & $1 / x^{3}$ & 7-Aminoflunitrazepam \\
\hline Alprazolam & 0.0120 & 0.0220 & 0.9987 & $1 / x^{3}$ & Alprazolam \\
\hline Midazolam & 0.0006 & 0.0012 & 0.9983 & $1 / x^{3}$ & Midazolam \\
\hline Clonazepam & 0.0110 & 0.0170 & 0.9985 & $1 / x^{3}$ & Clonazepam \\
\hline Oxazepam & 0.0100 & 0.0140 & 0.9993 & $1 / x^{3}$ & Oxazepam \\
\hline Temazepam & 0.0120 & 0.0190 & 0.9983 & $1 / x^{3}$ & Temazepam \\
\hline & & & & & $\begin{array}{ccc}0.0250 .05 & 0.25 \quad 0.5 & 1\end{array}$ \\
\hline
\end{tabular}

Fig. 1 Calibration parameters according to GTFCH guideline for the validation of analytical methods [28]: weighting factor, (R) correlation factor, (LOD) limit of detection, (LOQ) limit of quantification, and linear range (ng/mg) expressed as yellow bar

lengths reflect different time windows [6], it is preferable to present data collected from samples with comparable hair lengths (i.e., segmented cases). To increase the number of positive cases, we decided to also include non-segmented samples while remaining aware of the implications of the different hair lengths. 
Fig. 2 Parameters for recovery and matrix effects, acceptance criteria as green field according to the GTFCH guideline for the validation of analytical methods [28]: recovery $>50 \%$, matrix effect $75-125 \%$

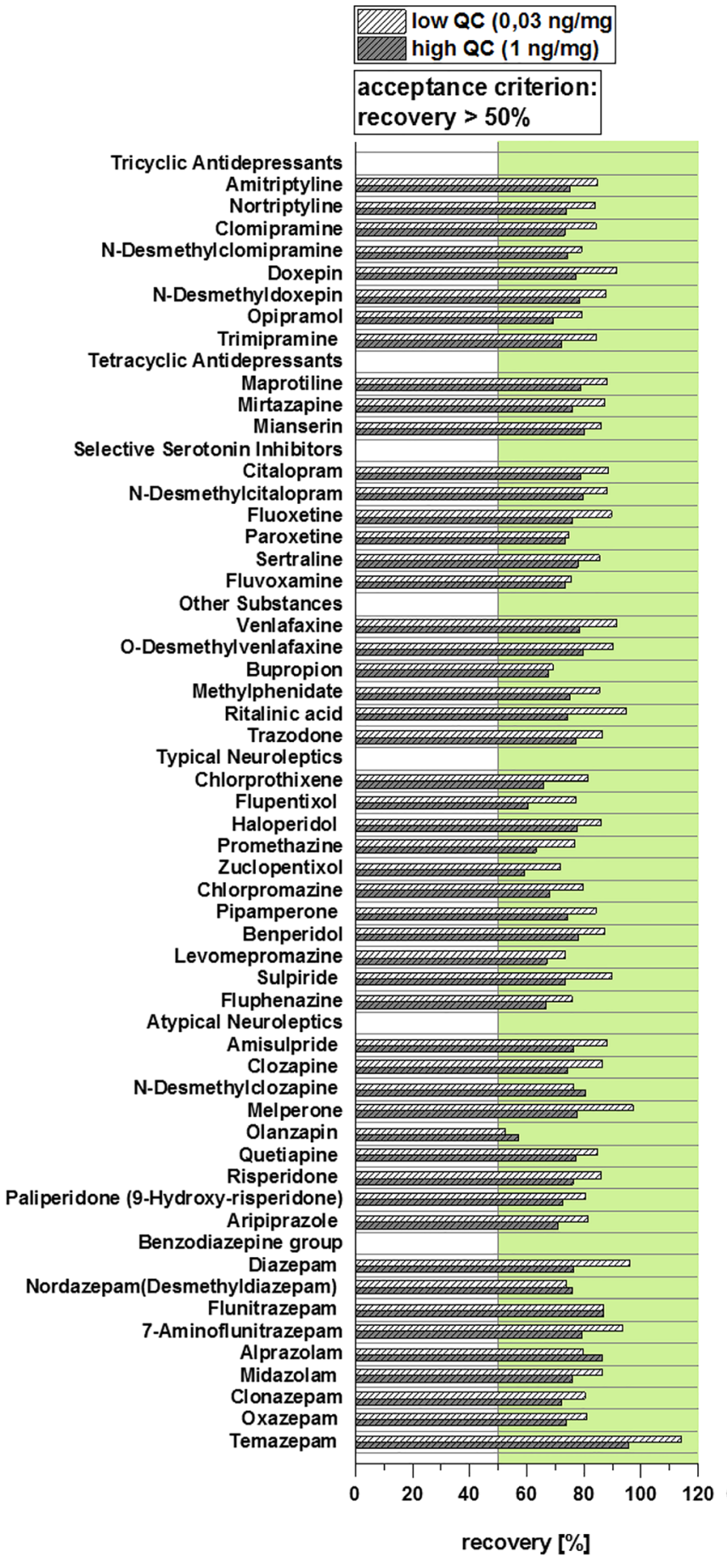

high QC $(1 \mathrm{ng} / \mathrm{mg})$

acceptance criterion: matrix effect $75-125 \%$

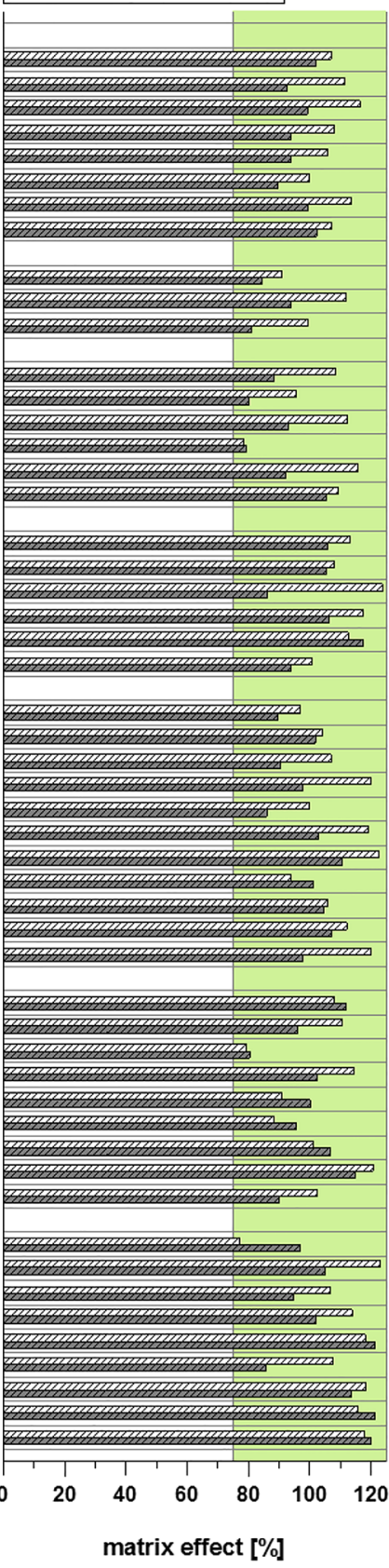

A review of published hair concentrations for the different analytes in this study was made [13-24, 33-48]. No published data were found for comparison for opipramol, trimipramine, fluvoxamine, $O$-desmethylvenlafaxine, benperidol, pipamperone, fluphenazine, and $N$-desmethylclozapine. The review revealed an inhomogeneity of detected concentrations due to varying investigated hair lengths, number of cases, and different origins of the sample (postmortal or living individuals). To illustrate this inhomogeneity, the overview for the substance quetiapine is given. The data ranged from investigations of single cases $[18,33]$ and small groups of living individuals ( $n=3,[24] ; n=10$ [15]) up to 22 postmortal hair samples [16]. The presented concentrations varied between 0.01 [24] and $13 \mathrm{ng} / \mathrm{mg}$ [16]. In our dataset, we presented data on quetiapine from 81 cases (see Table 4 ) with a concentration range of 0.003 (minimum)-9.79 $\mathrm{ng} / \mathrm{mg}$ (maximum). For mirtazapine, there were three publications [18, 24, 33] with data only from single cases, while we could present data from 


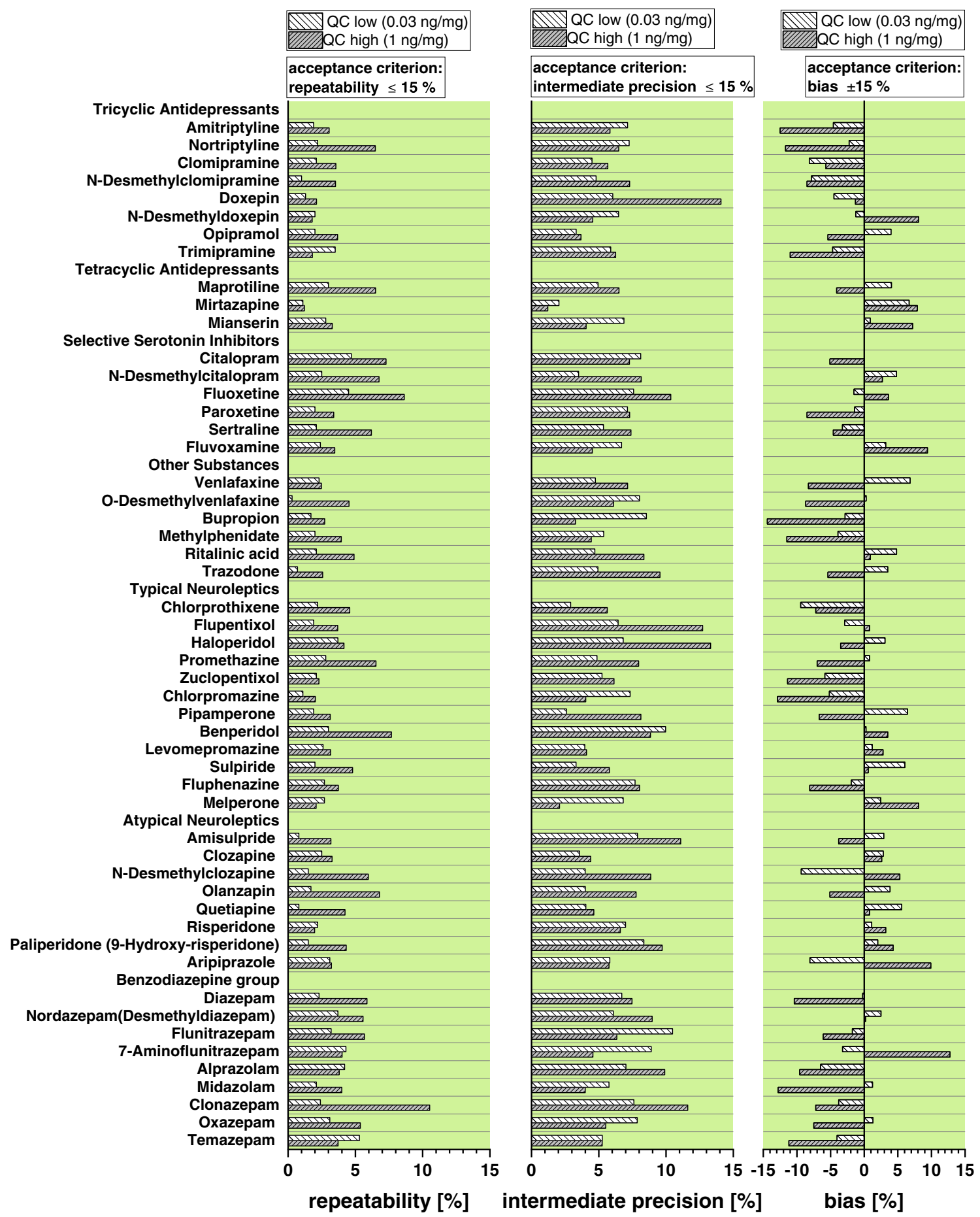

Fig. 3 Parameters for repeatability, intermediate precision, and bias, acceptance criteria as green field according to the GTFCH guideline for the validation of analytical methods [28]: repeatability $\leq 15 \%$, intermediate precision $\leq 15 \%$, bias $\pm 15 \%$

95 postmortem cases (see Table 4). Our findings agree with most of the published literature and extend the knowledge base for analytes that are seldom reported. The inhomogeneity of detected concentrations and the lack of sufficient data illustrates the importance of research in this field. There are several factors that can influence the amount of drug detected in the hair, for example, differences between individuals for hair growth, pigmentation, and cosmetic treatment, and frequency of drug consumption, and drug metabolism [2]. Analytical differences in extraction protocols, sample processing (e.g., cutting or powdering), and sample collection (especially segmentation [49]) have an influence on the amount of drug 
Table 3 Group 1 results: concentrations ( $\mathrm{ng} / \mathrm{mg})$ detected in segmented hair samples $(n=258)$

\begin{tabular}{|c|c|c|c|c|c|c|c|c|}
\hline Target substances & $n$ & Mean & $\begin{array}{l}5 \text { th } \\
\text { percentile }\end{array}$ & $\begin{array}{l}25 \text { th } \\
\text { percentile }\end{array}$ & Median & $\begin{array}{l}\text { 75th } \\
\text { percentile }\end{array}$ & $\begin{array}{l}95 \text { th } \\
\text { percentile }\end{array}$ & $\begin{array}{l}\text { 99th } \\
\text { percentile }\end{array}$ \\
\hline \multicolumn{9}{|l|}{ Tricyclic antidepressants } \\
\hline Amitriptyline & 23 & 0.98 & 0.010 & 0.022 & 0.17 & 1.18 & 5.27 & 6.46 \\
\hline Nortriptyline & 26 & 1.24 & 0.012 & 0.028 & 0.28 & 1.3 & 8.96 & 9.27 \\
\hline Nortriptyline/Amitriptyline Ratio & 21 & 1.56 & 0.26 & 0.63 & 1.09 & 1.83 & 5 & 5.51 \\
\hline Clomipramine $^{\mathrm{a}}$ & 2 & 0.69 & 0.047 & 0.047 & 0.69 & 1.35 & 1.35 & 1.35 \\
\hline$N$-Desmethylclomipramine ${ }^{\mathrm{a}}$ & 3 & 2.44 & 0.139 & 0.13 & 0.14 & 7.03 & 7.03 & 7.03 \\
\hline$N$-Desmethylclomipramine/Clomipramine Ratio & 2 & 4.08 & 2.94 & 2.94 & 4.08 & 5.23 & 5.23 & 5.23 \\
\hline Doxepin & 52 & 2.89 & 0.016 & 0.049 & 1.28 & 4.48 & 11.3 & 17.5 \\
\hline$N$-Desmethyldoxepin & 50 & 3.06 & 0.014 & 0.068 & 1.52 & 4.05 & 11.1 & 17.0 \\
\hline$N$-Desmethyldoxepin/Doxepin Ratio & 49 & 1.36 & 0.29 & 0.94 & 1.25 & 1.74 & 2.4 & 5.36 \\
\hline Opipramol & 32 & 2.61 & 0.006 & 0.026 & 0.37 & 1.85 & 17.6 & 18.9 \\
\hline Trimipramine & 37 & 2.43 & 0.011 & 0.034 & 0.36 & 2.72 & 11.0 & 24.2 \\
\hline \multicolumn{9}{|l|}{ Tetracyclic antidepressants } \\
\hline Mirtazapine & 56 & 1.31 & 0.006 & 0.066 & 0.30 & 1.54 & 6.88 & 11.7 \\
\hline \multicolumn{9}{|l|}{ Selective serotonin inhibitors } \\
\hline Citalopram & 82 & 6.23 & 0.008 & 0.061 & 0.97 & 6.37 & 15.4 & 155 \\
\hline$N$-Desmethylcitalopram & 68 & 1.61 & 0.008 & 0.052 & 0.73 & 2.41 & 6.3 & 8.65 \\
\hline$N$-Desmethylcitalopram/Citalopram Ratio & 68 & 0.334 & 0.051 & 0.19 & 0.29 & 0.46 & 0.64 & 0.86 \\
\hline Fluoxetine & 12 & 1.85 & 0.016 & 0.045 & 0.26 & 1.53 & 13.3 & 13.3 \\
\hline Paroxetine & 8 & 0.575 & 0.003 & 0.13 & 0.32 & 0.93 & 1.81 & 1.81 \\
\hline Sertraline & 19 & 6.51 & 0.012 & 0.29 & 0.73 & 2.26 & 59.7 & 59.7 \\
\hline \multicolumn{9}{|l|}{ Other substances } \\
\hline Venlafaxine & 27 & 3.14 & 0.005 & 0.024 & 0.79 & 4.96 & 12.7 & 18.0 \\
\hline$O$-Desmethylvenlafaxine & 25 & 2.32 & 0.009 & 0.088 & 1.31 & 3.73 & 7.27 & 8.15 \\
\hline$O$-Desmethylvenlafaxine/Venlafaxine Ratio & 25 & 1.74 & 0.035 & 0.67 & 0.93 & 1.97 & 3.48 & 15.0 \\
\hline Bupropion $^{\mathrm{a}}$ & 3 & 0.098 & 0.006 & 0.006 & 0.015 & 0.27 & 0.27 & 0.27 \\
\hline Methylphenidate & 6 & 0.26 & 0.004 & 0.006 & 0.039 & 0.42 & 1.09 & 1.09 \\
\hline Ritalinic acid & 21 & 0.12 & 0.004 & 0.006 & 0.015 & 0.044 & 0.22 & 1.96 \\
\hline Trazodone & 6 & 3.21 & 0.019 & 0.85 & 1.41 & 6.89 & 8.68 & 8.68 \\
\hline \multicolumn{9}{|l|}{ Typical neuroleptics } \\
\hline Chlorprothixene & 6 & 0.151 & 0.023 & 0.029 & 0.078 & 0.30 & 0.39 & 0.39 \\
\hline Flupentixol $^{\mathrm{a}}$ & 4 & 0.054 & 0.016 & 0.028 & 0.059 & 0.08 & 0.084 & 0.084 \\
\hline Haloperidol & 39 & 0.59 & 0.005 & 0.028 & 0.082 & 0.413 & 6.77 & 7.77 \\
\hline Promethazine & 49 & 0.59 & 0.006 & 0.022 & 0.089 & 0.329 & 3.84 & 6.11 \\
\hline Zuclopenthixol $^{\mathrm{a}}$ & 3 & 0.064 & 0.018 & 0.018 & 0.063 & 0.11 & 0.11 & 0.11 \\
\hline Pipamperone & 27 & 1.3 & 0.005 & 0.071 & 0.24 & 1.95 & 3.94 & 8.39 \\
\hline Benperidol $^{\mathrm{a}}$ & 2 & 0.014 & 0.003 & 0.003 & 0.014 & 0.024 & 0.024 & 0.024 \\
\hline Levomepromazine $^{\mathrm{a}}$ & 4 & 2.2 & 0.14 & 0.16 & 0.19 & 4.24 & 8.27 & 8.27 \\
\hline Sulpiride & 5 & 2.37 & 0.065 & 0.22 & 1.78 & 1.96 & 7.82 & 7.82 \\
\hline Fluphenazine $^{\mathrm{a}}$ & 1 & 0.035 & 0.035 & 0.035 & 0.035 & 0.035 & 0.035 & 0.035 \\
\hline Melperone & 49 & 1.17 & 0.004 & 0.011 & 0.042 & 0.42 & 8.06 & 13.6 \\
\hline \multicolumn{9}{|l|}{ Atypical neuroleptics } \\
\hline Amisulpride & 26 & 2.35 & 0.001 & 0.017 & 1.51 & 4.54 & 6.87 & 7.07 \\
\hline Clozapine & 34 & 1.9 & 0.002 & 0.005 & 0.013 & 2.07 & 11.6 & 13.4 \\
\hline$N$-Desmethylclozapine & 14 & 2.32 & 0.015 & 0.049 & 1.54 & 3.1 & 7.43 & 7.43 \\
\hline$N$-Desmethylclozapine/Clozapine Ratio & 14 & 0.66 & 0.124 & 0.48 & 0.53 & 0.79 & 1.57 & 1.57 \\
\hline Olanzapine & 10 & 0.19 & 0.008 & 0.079 & 0.14 & 0.27 & 0.45 & 0.45 \\
\hline Quetiapine & 47 & 1.15 & 0.007 & 0.019 & 0.30 & 1.41 & 5.05 & 9.8 \\
\hline Risperidone & 28 & 0.27 & 0.002 & 0.014 & 0.060 & 0.37 & 1.3 & 1.31 \\
\hline Paliperidone (9-hydroxyrisperidone) & 15 & 0.034 & 0.001 & 0.008 & 0.012 & 0.041 & 0.21 & 0.21 \\
\hline Paliperidone/Risperidone Ratio & 15 & 0.15 & 0.008 & 0.023 & 0.049 & 0.19 & 1.04 & 1.04 \\
\hline Aripiprazole & 6 & 0.384 & 0.025 & 0.044 & 0.14 & 0.51 & 1.43 & 1.43 \\
\hline \multicolumn{9}{|l|}{ Benzodiazepines } \\
\hline Diazepam & 55 & 0.48 & 0.006 & 0.018 & 0.12 & 0.40 & 3.35 & 4.27 \\
\hline Nordazepam (Desmethyldiazepam) & 35 & 1.0 & 0.015 & 0.051 & 0.30 & 0.79 & 6.7 & 8.64 \\
\hline Nordazepam/Diazepam Ratio & 35 & 1.41 & 0.25 & 0.59 & 1.16 & 1.98 & 3.01 & 4.11 \\
\hline Flunitrazepam $^{\mathrm{a}}$ & 2 & 0.19 & 0.13 & 0.13 & 0.19 & 0.25 & 0.25 & 0.25 \\
\hline 7-Aminoflunitrazepam ${ }^{\mathrm{a}}$ & 4 & 0.269 & 0.044 & 0.052 & 0.12 & 0.48 & 0.79 & 0.79 \\
\hline 7-Aminoflunitrazepam/Flunitrazepam Ratio & 2 & 2.24 & 1.34 & 1.34 & 2.24 & 3.13 & 3.13 & 3.13 \\
\hline Alprazolam ${ }^{\mathrm{a}}$ & 3 & 0.015 & 0.011 & 0.011 & 0.017 & 0.019 & 0.019 & 0.019 \\
\hline Midazolam & 22 & 1.31 & 0.006 & 0.015 & 0.036 & 0.11 & 1.16 & 25.8 \\
\hline Oxazepam & 17 & 0.11 & 0.016 & 0.029 & 0.055 & 0.17 & 0.62 & 0.62 \\
\hline Temazepam & 9 & 0.15 & 0.012 & 0.040 & 0.062 & 0.13 & 0.66 & 0.66 \\
\hline
\end{tabular}

${ }^{\mathrm{a}}$ Detection of $n<5$ cases

Group 1 only contains cases in which the hair sample was 4-cm long and cut into two segments: segment 1 was $0-2 \mathrm{~cm}$ from the proximal end, and segment 2 was $2-4 \mathrm{~cm}$ from the proximal end. The number of cases is given as $n$ 
Table 4 Group 2 results: concentrations (ng/mg) detected in segmented hair samples $(n=258)$ and non-segmented samples $(n=162)($ total $n=420)$

\begin{tabular}{|c|c|c|c|c|c|c|c|c|}
\hline Target substances & $n$ & Mean & $\begin{array}{l}\text { 5th } \\
\text { percentile }\end{array}$ & $\begin{array}{l}25 \text { th } \\
\text { percentile }\end{array}$ & Median & $\begin{array}{l}\text { 75th } \\
\text { percentile }\end{array}$ & $\begin{array}{l}\text { 95th } \\
\text { percentile }\end{array}$ & $\begin{array}{l}\text { 99th } \\
\text { percentile }\end{array}$ \\
\hline \multicolumn{9}{|l|}{ Tricyclic antidepressants } \\
\hline Amitriptyline & 49 & 2.27 & 0.0102 & 0.0925 & 0.338 & 2.24 & 12.4 & 17.5 \\
\hline Nortriptyline & 51 & 2.5 & 0.0088 & 0.0618 & 0.403 & 1.8 & 18.3 & 19.9 \\
\hline Nortriptyline/Amitriptyline Ratio & 45 & 1.39 & 0.148 & 0.638 & 1.09 & 1.76 & 5.00 & 5.51 \\
\hline Clomipramine $^{\mathrm{a}}$ & 4 & 2.08 & 0.0471 & 0.696 & 2.1 & 3.46 & 4.08 & 4.08 \\
\hline$N$-Desmethylclomipramine & 6 & 3.44 & 0.0113 & 0.139 & 2.64 & 7.03 & 8.21 & 8.21 \\
\hline$N$-Desmethylclomipramine/Clomipramine Ratio ${ }^{\mathrm{a}}$ & 4 & 3 & 1.8 & 1.91 & 2.48 & 4.08 & 5.23 & 5.23 \\
\hline Doxepin & 84 & 3.75 & 0.0208 & 0.0525 & 1.16 & 5.17 & 13.6 & 54 \\
\hline$N$-Desmethyldoxepin & 82 & 3.28 & 0.023 & 0.0615 & 1.45 & 5.87 & 11.1 & 23.1 \\
\hline N-Desmethyldoxepin/Doxepin Ratio & 76 & 1.23 & 0.144 & 0.837 & 1.23 & 1.65 & 2.33 & 2.9 \\
\hline Opipramol & 49 & 2.06 & 0.0069 & 0.0303 & 0.491 & 1.79 & 11.2 & 18.9 \\
\hline Trimipramine & 53 & 4.92 & 0.0155 & 0.0812 & 1.23 & 5.28 & 24.2 & 67.8 \\
\hline \multicolumn{9}{|l|}{ Tetracyclic antidepressants } \\
\hline Maprotiline $^{\mathrm{a}}$ & 1 & 5.71 & 5.71 & 5.71 & 5.71 & 5.71 & 5.71 & 5.71 \\
\hline Mirtazapine & 95 & 1.39 & 0.0065 & 0.0775 & 0.56 & 1.78 & 6.25 & 11.7 \\
\hline \multicolumn{9}{|l|}{ Selective serotonin inhibitors } \\
\hline Citalopram & 133 & 4.94 & 0.0087 & 0.035 & 0.714 & 4.84 & 15.4 & 66.9 \\
\hline$N$-Desmethylcitalopram & 108 & 1.56 & 0.008 & 0.028 & 0.635 & 2.15 & 6.32 & 8.65 \\
\hline$N$-Desmethylcitalopram/Citalopram Ratio & 108 & 0.394 & 0.0658 & 0.206 & 0.332 & 0.482 & 0.869 & 1.87 \\
\hline Fluoxetine & 18 & 2.59 & 0.0166 & 0.0505 & 0.403 & 4.51 & 13.3 & 13.3 \\
\hline Paroxetine & 16 & 2.28 & 0.00335 & 0.211 & 0.405 & 1.85 & 16.6 & 16.6 \\
\hline Sertraline & 39 & 3.65 & 0.0122 & 0.0695 & 0.404 & 1.82 & 43.4 & 59.7 \\
\hline Fluvoxamine $^{\mathrm{a}}$ & 1 & 0.102 & 0.102 & 0.102 & 0.102 & 0.102 & 0.102 & 0.102 \\
\hline \multicolumn{9}{|l|}{ Other substances } \\
\hline Venlafaxine & 47 & 3.26 & 0.008 & 0.064 & 1.95 & 4.96 & 12.7 & 18 \\
\hline$O$-Desmethylvenlafaxine & 45 & 2.39 & 0.00905 & 0.289 & 1.76 & 3.58 & 7.27 & 8.2 \\
\hline$O$-Desmethylvenlafaxine/Venlafaxine Ratio & 45 & 1.54 & 0.132 & 0.573 & 0.924 & 1.76 & 3.48 & 15 \\
\hline Bupropion & 5 & 0.0701 & 0.006 & 0.0155 & 0.0164 & 0.0397 & 0.273 & 0.273 \\
\hline Methylphenidate & 9 & 0.22 & 0.0042 & 0.018 & 0.0515 & 0.218 & 1.09 & 1.09 \\
\hline Ritalinic acid & 30 & 0.107 & 0.004 & 0.0072 & 0.0225 & 0.0672 & 0.223 & 1.96 \\
\hline Trazodone & 8 & 2.47 & 0.0081 & 0.253 & 0.946 & 4.33 & 8.68 & 8.68 \\
\hline \multicolumn{9}{|l|}{ Typical neuroleptics } \\
\hline Chlorprothixene & 11 & 4.56 & 0.0181 & 0.029 & 0.104 & 0.392 & 42.2 & 42.2 \\
\hline Flupentixol & 8 & 0.0831 & 0.016 & 0.0303 & 0.059 & 0.112 & 0.246 & 0.246 \\
\hline Haloperidol & 72 & 0.639 & 0.0057 & 0.0375 & 0.0924 & 0.367 & 6.44 & 9.74 \\
\hline Promethazine & 78 & 0.58 & 0.0064 & 0.026 & 0.0874 & 0.329 & 3.84 & 6.71 \\
\hline Zuclopenthixol $^{\mathrm{a}}$ & 3 & 0.0645 & 0.0188 & 0.0188 & 0.0639 & 0.111 & 0.111 & 0.111 \\
\hline Pipamperone & 53 & 1.28 & 0.0058 & 0.0261 & 0.209 & 1.56 & 5.57 & 11.4 \\
\hline Benperidol & 2 & 0.0141 & 0.00385 & 0.00385 & 0.0141 & 0.0244 & 0.0244 & 0.0244 \\
\hline Levomepromazine & 8 & 1.58 & 0.021 & 0.086 & 0.194 & 1.89 & 8.27 & 8.27 \\
\hline Sulpiride & 39 & 3.65 & 0.0122 & 0.0695 & 0.404 & 1.82 & 43.4 & 59.7 \\
\hline Fluphenazine $^{\mathrm{a}}$ & 1 & 0.0357 & 0.0357 & 0.0357 & 0.0357 & 0.0357 & 0.0357 & 0.0357 \\
\hline Melperone & 85 & 1.79 & 0.0052 & 0.0165 & 0.108 & 0.925 & 10.7 & 18.6 \\
\hline \multicolumn{9}{|l|}{ Atypical neuroleptics } \\
\hline Amisulpride & 43 & 1.89 & 0.002 & 0.00575 & 0.822 & 3.33 & 6.87 & 7.68 \\
\hline Clozapine & 56 & 2.62 & 0.00225 & 0.00747 & 0.023 & 3.21 & 13.4 & 23.2 \\
\hline$N$-Desmethylclozapine & 25 & 2.64 & 0.0267 & 0.062 & 1.65 & 5.02 & 7.26 & 7.43 \\
\hline$N$-Desmethylclozapine/Clozapine Ratio & 25 & 0.571 & 0.0754 & 0.384 & 0.52 & 0.689 & 1.32 & 1.57 \\
\hline Olanzapine & 15 & 0.179 & 0.00855 & 0.0597 & 0.176 & 0.271 & 0.458 & 0.458 \\
\hline Quetiapine & 81 & 1.15 & 0.00735 & 0.0407 & 0.393 & 1.42 & 5.05 & 9.8 \\
\hline Risperidone & 56 & 0.379 & 0.0044 & 0.0283 & 0.121 & 0.577 & 1.32 & 3.06 \\
\hline Paliperidone (9-Hydroxyrisperidone) & 35 & 0.0304 & 0.00185 & 0.0077 & 0.0121 & 0.036 & 0.128 & 0.215 \\
\hline Paliperidone/Risperidone Ratio & 35 & 0.17 & 0.00469 & 0.0175 & 0.058 & 0.164 & 1 & 1.04 \\
\hline Aripiprazole & 12 & 1.21 & 0.0257 & 0.0671 & 0.504 & 1.36 & 7.5 & 7.5 \\
\hline \multicolumn{9}{|l|}{ Benzodiazepines } \\
\hline Diazepam & 110 & 0.43 & 0.00645 & 0.0243 & 0.121 & 0.407 & 2.14 & 3.71 \\
\hline Nordazepam(Desmethyldiazepam) & 73 & 0.729 & 0.03 & 0.0626 & 0.24 & 0.728 & 3.64 & 8.64 \\
\hline Nordazepam/Diazepam Ratio & 71 & 1.28 & 0.256 & 0.616 & 1.13 & 1.8 & 2.88 & 4.11 \\
\hline Flunitrazepam ${ }^{\mathrm{a}}$ & 3 & 0.14 & 0.0311 & 0.0311 & 0.135 & 0.253 & 0.253 & 0.253 \\
\hline 7-Aminoflunitrazepam & 5 & 0.247 & 0.044 & 0.0605 & 0.157 & 0.181 & 0.792 & 0.792 \\
\hline 7-Aminoflunitrazepam/Flunitrazepam Ratio ${ }^{a}$ & 3 & 3.17 & 1.34 & 1.34 & 3.13 & 5.04 & 5.04 & 5.04 \\
\hline Alprazolam $^{\mathrm{a}}$ & 4 & 0.0371 & 0.011 & 0.0141 & 0.0182 & 0.0602 & 0.101 & 0.101 \\
\hline Midazolam & 33 & 1.08 & 0.0059 & 0.0156 & 0.0375 & 0.216 & 3.53 & 25.8 \\
\hline Oxazepam & 26 & 0.117 & 0.0178 & 0.0299 & 0.0512 & 0.174 & 0.441 & 0.629 \\
\hline Temazepam & 16 & 0.127 & 0.0123 & 0.0334 & 0.0589 & 0.145 & 0.667 & 0.667 \\
\hline
\end{tabular}

${ }^{\text {a }}$ Detection of $n<5$ cases

Group 2 contains cases in which the hair sample was segmented (group $1, n=258$ ) and cases in which no segmentation was possible. Cases with sample hair lengths shorter or longer than $4 \mathrm{~cm}$ were also included $(n=152)$. The number of cases is given as $n$ 
Table 5 Cases with positive findings in hair and blood, urine, or organ tissue

Target substances $\quad$ Number of cases with target substance detected in hair

(n)

Tricyclic antidepressants

$\begin{array}{ll}\text { Amitriptyline } & 4 \\ \text { Nortriptyline } & 5 \\ \text { Clomipramine }^{\mathrm{a}} & 4 \\ N \text {-Desmethylclomipramine } & 6 \\ \text { Doxepin } & 8 \\ N \text {-Desmethyldoxepin } & 82 \\ \text { Opipramol } & 49 \\ \text { Trimipramine } & 53\end{array}$

Tetracyclic antidepressants

Maprotiline $^{\mathrm{a}}$

Mirtazapine

49

51

4

6

84

82

49

53

1

95

Selective serotonin inhibitors

Citalopram

$N$-Desmethylcitalopram

Fluoxetine

Paroxetine

Sertraline

Fluvoxamine $^{\mathrm{a}}$

Other substances

Venlafaxine

$O$-Desmethylvenlafaxine

Bupropion

Methylphenidate

Ritalinic acid

Typical neuroleptics

Chlorprothixene

Flupentixol

Haloperidol

Promethazine

Zuclopenthixol

Sulpiride

Fluphenazine $^{\mathrm{a}}$

Melperone

Atypical neuroleptics

Amisulpride

Clozapine

$N$-Desmethylclozapine

Olanzapine

Quetiapine

Risperidone

Paliperidone (9-Hydroxy-risperidone)
Number of cases with target substance detected in blood, urine, or organ tissue

(Frequency of detection, $\%$ and total number)

$53.1(26)$

47.1 (24)

75 (3)

16.7 (1)

$52.4(44)$

31.7 (26)

38.7 (19)

$60.4(32)$

$100(1)$

$45.3(43)$

$37.6(50)$

27.5 (30)

38.9 (7)

37.5 (6)

43.6 (17)

0

55.3 (26)

28.9 (13)

0

0

3.3 (1)

45.5 (5)

37.5 (3)

19.4 (14)

30.8 (24)

$33.3(1)$

0

0

24.7 (21)

$38.1(16)$

35.7 (20)

52 (13)

40 (6)

$38.3(31)$

$19.6(11)$

$17.1(6)$

${ }^{\text {a }}$ Detection of $n<5$ cases

Information on the detection of the target analytes in blood, urine, or organ tissue taken at autopsy was obtained from a previous publication [25] 
Fig. 4 The frequency of a decrease or increase of analyte concentration from segment [S2] $(2-4 \mathrm{~cm})$ to segment $[\mathrm{S} 1](0-$

$2 \mathrm{~cm}$ ) for $n=258$ cases with a segmental analysis. The absolute number of cases is displayed as $n$ for each analyte

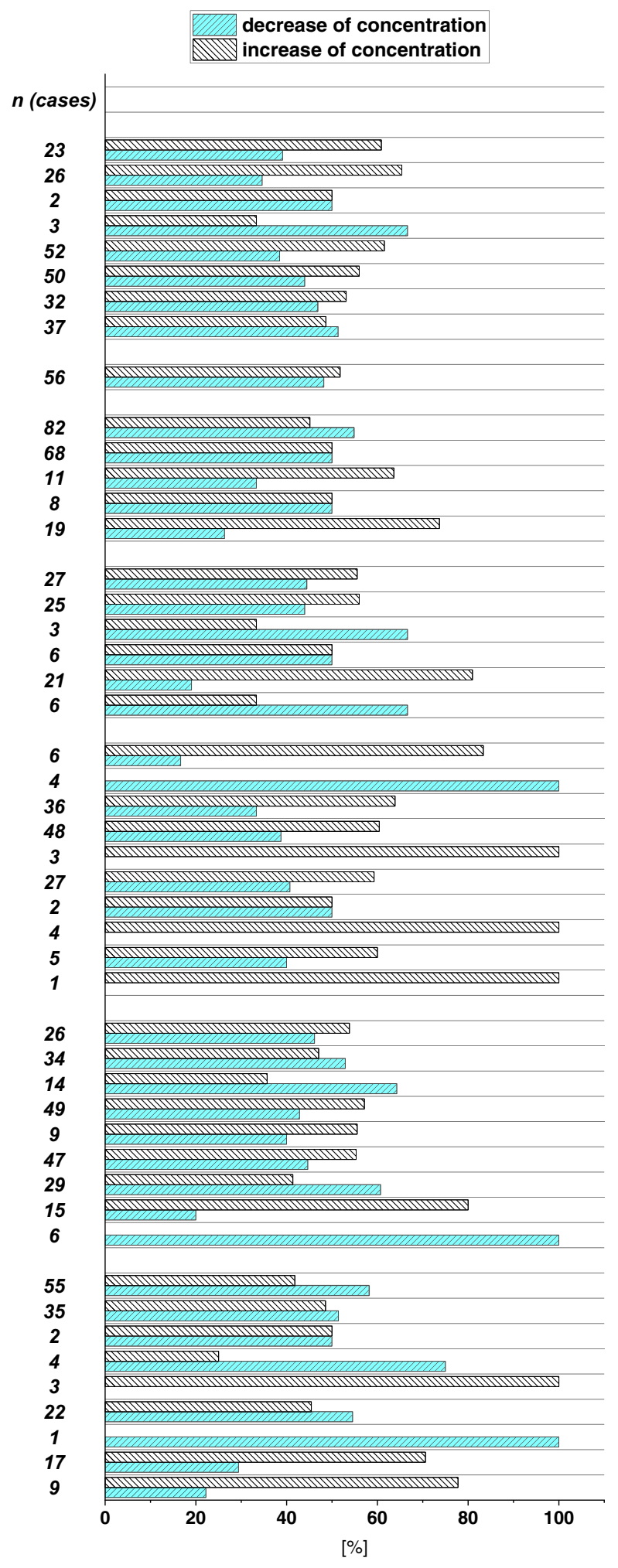

extracted from the hair matrix [2, 50]. External proficiency testing can help to establish better comparability among the conventional methods [2] but is only available for common drugs of abuse and not for the described substances to date. Therefore, comparison with published data from postmortem hair samples should be undertaken with great care. To achieve better comparability, it is recommended that laboratories establish their own databases [50]. Because of these implications, it is not possible to exactly correlate the amount of a substance ingested with the concentration detected in hair [2, 
$6,10,50]$. There have been some useful applications of hair analysis in forensic toxicology and the interpretation of postmortem cases [8]. Preferably, multi-sectional analyses should be undertaken for comparison of different periods to monitor changes in the pattern of substance use over a long time $[6,8]$.

\section{Metabolite to Parent Drug Ratios}

Differentiation of drug use from external contamination is considered a limitation in hair analysis [32]. It has been proposed that relevant metabolites could be detected to minimize misinterpretation [32]. In the case of cocaine, several proposals have been made for differentiation of use/external contamination because some of its metabolites are also found in cocaine powder [51]. Metabolite ratios have then been useful for interpretation of these results.

Wherever possible, we analyzed the metabolite to parent drug ratio (Table 4). Such ratios have been rarely reported [34] for the investigated analytes. Table 7 compares our findings for the ratios of nortriptyline/amitriptyline, $\mathrm{N}$ desmethyldoxepin/doxepin, and $N$-desmethylclomipramine/ clomipramine with the findings of Pragst et al. for patients undergoing long-term treatment with tricyclic antidepressants [34]. Our findings were comparable for doxepin and amitriptyline, although our maximum values were higher.

\section{Concentrations Detected at the Time of Death and in Postmortem Hair}

The agreement between the concentration detected at the time of death and that detected in the hair sample ranged between full and no agreement (Table 5). In cases with no agreement, it could be shown that these substances were repeatedly been intake in the months prior to death, but not acutely. This knowledge would be inaccessible to the forensic investigation if only blood or urine samples were analyzed because they only reflect the intake in the hours before death. There may be bias here because some analytes had very low detection rates (i.e., < five cases, shown in italic font in Table 5). Several factors can lead to such discrepancies. The sensitivities of the applied methods for matrices that reveal acute intake can be a factor if only low levels of the drug are detected. Second, the deceased might have stopped using a non-favorable drug weeks or days before the time of death, but it will still be detectable in hair. Again, this supports the use of hair in postmortem analysis for understanding history of use [8].

\section{Segmental Analysis}

Figure 4 shows the proportions of decreases and increases in the concentrations from segment 2 ([S2] 2-4 cm from the proximal end) to segment 1 ([S1] $0-2 \mathrm{~cm}$ from the proximal end). A decrease in concentration from segment 2 to segment
1 could indicate reduction of drug intake over at least the last 4 months before the time of death. Such a reduction could be associated with a loss of compliance for intake of a prescribed medication. Conversely, an increase in concentration from segment 2 to segment 1 could indicate an increase in drug intake, which could be associated with the start of drug therapy. According to our results, no substance is more likely to show a trend towards an increase or decrease in concentration. However, there were substances that showed a trend towards an increase or decrease, which should not be overinterpreted since those substances were only detected in a few cases $(n$ $<5)$.

\section{Interpretation of high concentrations with possible bias from contamination}

Although the results from postmortem hair analysis can be very helpful, critical interpretation of the results should be undertaken because false positive results from external contamination are an issue [32]. Postmortal incorporation of drugs into the hair can occur through body fluids (e.g., blood, sweat, or putrefaction fluid) or there can be external contamination from environmental pollution [32]. One mechanism of drug incorporation is via sweat since it is known to contain drugs present in blood [8]. Therefore, excessive sweating during a long agonal phase in the process of dying can also affect the hair concentration. The investigator should be aware of these mechanisms in order to avoid false interpretation of long-term exposure [32]. The results of segmental analysis could indicate contamination if the concentrations are homogenous or consecutive. Taking four cases from the dataset as an example (Table 6), we want to highlight these issues to encourage other investigators to do the same. Homogenous concentrations can be observed in the results of cases 1 and 2. In case 1 , where a woman was found dead in a bathing tub with cuts to her arms, there are extremely high concentrations of citalopram and its metabolite $N$-desmethylcitalopram in both the segments (136 and $176 \mathrm{ng} / \mathrm{mg}$ citalopram; 5.46 and $4.77 \mathrm{ng} / \mathrm{mg} N$-desmethylcitalopram). A lethal concentration of citalopram was found in the postmortem blood sample, and a high amount of citalopram was found in the stomach contents. In addition, the ratio of the metabolite to the parent $\operatorname{drug}(0.033$; Table 6$)$ is one-tenth that of the mean ratio for the whole dataset of segmented cases (0.334; Table 3). Similar results are observed for doxepin and its metabolite in case 2 with a $N$-desmethyldoxepin/doxepin ratio of 0.018 (Table 6) and a mean ratio of 1.36 for all the segmented cases (Table 3 ). Furthermore, in case 2, the concentrations of citalopram, doxepin, melperone, trimipramine, and sertraline are high and homogenous throughout the two segments, and these substances were found in lethal concentrations in the blood samples. Mirtazapine and fluoxetine were not found in the postmortem blood but were detected in high levels in hair. 
Table 6 cases possibly influenced by contamination

\begin{tabular}{|c|c|c|c|c|c|}
\hline & \multirow[t]{2}{*}{ Target substances } & \multicolumn{2}{|c|}{$\begin{array}{l}\text { Concentrations } \\
\text { detected in hair (ng/ } \\
\mathrm{mg})\end{array}$} & \multicolumn{2}{|c|}{$\begin{array}{l}\text { Concentration detected at time } \\
\text { of death }\end{array}$} \\
\hline & & $\mathrm{S}^{\mathrm{a}}$ & $\mathrm{S} 2^{\mathrm{b}}$ & $\begin{array}{l}\text { Blood } \\
(\mathrm{mg} / \mathrm{L})\end{array}$ & $\begin{array}{l}\text { Stomach sontents } \\
(\mathrm{mg} / \mathrm{L})\end{array}$ \\
\hline \multirow[t]{3}{*}{ Case 1} & Citalopram & 136 & 173 & 54.1 & 6400 \\
\hline & $N$-Desmethylcitalopram & 5.46 & 4.77 & 0.36 & 17.2 \\
\hline & $N$-Desmethylcitalopram/Citalopram Ratio & 0.033 & & & \\
\hline \multirow[t]{13}{*}{ Case 2} & Citalopram & 16.7 & 14.0 & 57.4 & 2460 \\
\hline & $N$-Desmethylcitalopram & 2.04 & 1.63 & - & - \\
\hline & $N$-Desmethylcitalopram/Citalopram Ratio & 0.119 & & & \\
\hline & Diazepam & 0.269 & 0.228 & 0.023 & - \\
\hline & Doxepin & 8.68 & 8.46 & 3.18 & 128 \\
\hline & $N$-Desmethldoxepin & 0.179 & 0.136 & - & - \\
\hline & $N$-Desmethyldoxepin/Doxepin Ratio & 0.018 & & & \\
\hline & Fluoxetine & 12.6 & 13.9 & - & - \\
\hline & Melperone & 6.18 & 5.84 & 3.90 & 153 \\
\hline & Midazolam & 0.099 & 0.13 & - & - \\
\hline & Mirtazapine & 1.20 & 1.16 & - & - \\
\hline & Sertraline & 54.251 & 65.0 & 4.32 & 90 \\
\hline & Trimipramine & 9.689 & 12.2 & 1.13 & 75 \\
\hline \multirow[t]{6}{*}{ Case 3} & Sertraline & 63.313 & 23.4 & 6.42 & 186 \\
\hline & Mirtazapine & 14.845 & 8.49 & 10.0 & 206 \\
\hline & Diazepam & 4.586 & 2.82 & 0.81 & - \\
\hline & Nordazepam (Desmethyldiazepam) & 0.1917 & 0.278 & 0.043 & - \\
\hline & Oxazepam & 0.0182 & 0.0149 & 0.003 & - \\
\hline & & $\mathrm{S}^{\mathrm{c}}$ & & & \\
\hline \multirow[t]{6}{*}{ Case 4} & Chlorprothixene & 42.2 & & 0.11 & 10.3 \\
\hline & Amitriptyline & 0.036 & & - & \\
\hline & Doxepin & 25.8 & & 0.36 & 12.3 \\
\hline & $N$-Desmethldoxepin & 1.81 & & 0.09 & \\
\hline & $N$-Desmethyldoxepin/Doxepin Ratio & 0.070 & & & \\
\hline & Trimipramine & 67.8 & & 1.09 & 29.7 \\
\hline
\end{tabular}

${ }^{a} \mathrm{~S} 1$ (segment 1): 0-2 cm from the proximal end of the hair shaft

${ }^{\mathrm{b}} \mathrm{S} 2$ (segment 2): $2-4 \mathrm{~cm}$ from the proximal end of the hair shaft

${ }^{\mathrm{c}} \mathrm{S} 0$ (full segment): full length of $1.5 \mathrm{~cm}$

Cases with high drug concentrations in hair are shown. The results of the postmortem hair analyses are compared with the concentrations of the same analytes found in blood and the stomach contents
Therefore, external contamination is not likely and these results could point to long-term exposure to mirtazapine and fluoxetine. However, even if, in the presented cases, potentially lethal blood concentrations have been found, a contamination also occurs with lower blood concentrations. Therefore, a lethal blood concentration may be not a criterion for a possible contamination. The scenario of case 1 , a body in a bathtub filled with water and blood from wounds of the descendant, is an example how hair can be contaminated. Case 3 shows a different result constellation with high concentrations in the first segment for all substances and concentrations in the second segment that are about half those in the first segment. Lethal blood concentrations were found for all these substances. The phenomenon of axial diffusion throughout segments, described by Kintz et al. [52], should also be considered. Other authors $[13,17]$ have proposed that internal contamination of distal segments can occur from sweat/sebum or aggressive hair treatment. Differences in hair growth or alignment of hair during cutting can also affect the concentrations in neighboring segments $[24,49]$. Finally, case 4 illustrates the discussed issues for a sample with no segmentation, which, in this case, was because of the short hair length $(1.5 \mathrm{~cm})$. In this 
Table 7 Comparison of metabolite/parent drug ratios with data from Pragst et al. [34]

\begin{tabular}{lllll}
\hline Metabolite/parent drug ratio & $\begin{array}{l}\text { Number } \\
\text { of cases }\end{array}$ & $\begin{array}{l}\text { Minimum } \\
\text { concentration } \\
(\mathrm{ng} / \mathrm{mg})\end{array}$ & $\begin{array}{l}\text { Maximum } \\
\text { concentration } \\
(\mathrm{ng} / \mathrm{mg})\end{array}$ & $\begin{array}{l}\text { Median } \\
\text { concentration } \\
\text { (ng/mg) }\end{array}$ \\
\hline Results from group 2 $(n=420)$ & & & & \\
Nortriptyline/Amitriptyline & 45 & 0.083 & 5.51 & 1.09 \\
$N$-Desmethylclomipramine/Clomipramine & 4 & 1.8 & 5.22 & 2.48 \\
$N$-Desmethyldoxepin/Doxepin & 76 & 0.018 & 2.9 & \\
Results from Pragst et al. [34] & & & & \\
Nortriptyline/Amitriptyline & 25 & 0.1 & 2.6 & \\
$N$-Desmethylclomipramine/Clomipramine & 7 & 0.2 & 0.86 & \\
$N$-Desmethyldoxepin/Doxepin & 6 & 0.33 & 1.38 & \\
\hline
\end{tabular}

The metabolite/parent drug ratios found in group $2(n=420$ for segmented and non-segmented cases combined) are compared with those from the work of Pragst et al. [34] case, high levels of chlorprothixene, trimipramine, and doxepin were observed in the hair, and these substances were found in the postmortem blood. The ratio of doxepin and its metabolite $(N$-desmethyldoxepin/doxepin $=0.07$; Table 6$)$ is much lower than the mean ratio for all the segmented cases (1.36; Table 3). This may indicate a mechanism of contamination that is not detectable without segmentation. In comparison with the concentration detected in case 4 , some studies have found lower concentrations for chlorprothixene (mean $0.38 \mathrm{ng} / \mathrm{mg}$ ) [17], and others have found similar concentrations $(30 \mathrm{ng} / \mathrm{mg})$ [23]. This difference is difficult to interpret because of the lack of data available on antidepressants and antipsychotics in general. The data from these four cases was not removed from the datasets in Tables 3 and 4 since contamination could only be assumed. Furthermore, the presentation in percentiles allows the interpretation of high hair concentrations.

\section{Limitations and Strengths}

A comprehensive and sensitive method for the determination of 52 analytes was developed and successfully validated according to the guidelines of the GTFCh [28]. The method showed excellent sensitivity with low limits of detection (pg/ mg range), selectivity, accuracy, and stability.

The major limitation of the presented data is the postmortem origin of the hair samples. Besides the lack of information on hair treatment, exact information on drug exposure (e.g., dose and duration of intake) is rarely available in postmortem cases; therefore, quantitative data from postmortem cases cannot be used to discriminate if there was constant or sporadic exposure. Kintz et al. [32] described the influence of external contamination from body fluids or environmental contamination in postmortem toxicology and its risk of false-positive interpretations of long-term exposure to drugs. Since a segmentation was not possible in all cases, two datasets were presented. The samples in the second dataset were a mix of hair lengths shorter and longer than $4 \mathrm{~cm}$, which introduces bias because the window of detection depends on the hair length [2]. Other authors [17] have published results with similar bias from varying hair lengths and presented the concentrations as averages [16]. A review of the published literature shows that variation in investigated hair lengths is common, and length limitations should be considered when comparing data to avoid false interpretations.

The presented data are informative and valuable for numerous drugs in postmortem hair and may be helpful in future casework when interpreted carefully. To the best of our knowledge, this study is the first that presents postmortem hair concentrations of antidepressants, antipsychotics, and benzodiazepines in such a comprehensive way. An overview of the literature revealed that our data are comparable with the work of other authors in some areas but extend the field of knowledge for many analytes. Furthermore, we have presented metabolite ratios for eight analytes that could be helpful in differentiation between drug use and external contamination. We have discussed cases from acute intoxication in the light of the issue of external contamination in postmortem hair analysis and considered how it could be addressed by segmental analysis.

\section{Conclusions}

The main aim of this work was to validate a sensitive method for detection of 52 analytes (antidepressants, antipsychotics, and benzodiazepines) in hair and to apply it to preselected postmortem cases, which could help correct the lack of comprehensive data on postmortem hair concentrations for drugs other than drugs of abuse. In accord with previous work, our informative study presents quantitative data for 49 substances in hair samples from 420 postmortem cases. These data can help in the assessment of certain case constellations when interpreted carefully and with an emphasis on exclusion of 
false positive results from external contamination. We have addressed these important issues, which should be considered by forensic investigators, in four example cases. Postmortem hair analysis can have further applications such as proof of repetitive exposure, proof of administration, or use as a tool for exclusion of exposure [8]. If the frequency of detected drugs per case reveals multi-exposure to drugs, it should be considered as a history of changing treatment regimens as a result of low efficiency or bad compliance. Retrospective toxicological data from postmortem cases can be valuable in risk assessment and the search for better treatment strategies [53].

Acknowledgments We thank Gabrielle David, PhD, from Edanz Group (www.edanzediting.com/ac) for editing a draft of this manuscript. The authors would like to Ms. Janine Stramm, Ms. Jenny Liang, and Mr. Mahir Uzonovic for their help with the sample preparation.

Funding Information Open Access funding provided by Projekt DEAL.

\section{Compliance with Ethical Standards}

Conflict of Interest The authors declare that they have no conflict of interest and that third parties, especially any pharmaceutical company, did not sponsor this study.

Ethical Approval This study was a retrospective study on postmortem cases. Therefore, this article does not contain any study on living human participants or animals performed by the authors.

Informed Consent Informed consent was waived due to the retrospective nature of this study.

Open Access This article is licensed under a Creative Commons Attribution 4.0 International License, which permits use, sharing, adaptation, distribution and reproduction in any medium or format, as long as you give appropriate credit to the original author(s) and the source, provide a link to the Creative Commons licence, and indicate if changes were made. The images or other third party material in this article are included in the article's Creative Commons licence, unless indicated otherwise in a credit line to the material. If material is not included in the article's Creative Commons licence and your intended use is not permitted by statutory regulation or exceeds the permitted use, you will need to obtain permission directly from the copyright holder. To view a copy of this licence, visit http://creativecommons.org/licenses/by/4.0/.

\section{References}

1. Kintz P, Salomone A, Vincenti M. Hair analysis in clinical and forensic toxicology. Boston: Academic Press; 2015.

2. Pragst F, Balikova MA. State of the art in hair analysis for detection of drug and alcohol abuse. Clin Chim Act. 2006;370(1-2):17-49.

3. Rothe M, Pragst F, Thor S, Hunger J. Effect of pigmentation on the drug deposition in hair of grey-haired subjects. Forensic Sci Int. 1997;84(1):53-60.

4. Yegles M. Pitfalls in hair analysis: cosmetic treatment. Ann Toxicol Anal. 2005;17:275-18.

5. Cuypers E, Flanagan RJ. The interpretation of hair analysis for drugs and drug metabolites. Clin Toxicol. 2018;56(2):90-100.
6. Tsanaclis L, Wicks JF. Patterns in drug use in the United Kingdom as revealed through analysis of hair in a large population sample. Forensic Sci Int. 2007;170(2-3):121-8.

7. Hoiseth G, Arnestad M, Karinen R, Morini L, Rogde S, Sempio C, et al. Is hair analysis useful in postmortem cases? J Anal Toxicol. 2018;42(1):49-54.

8. Kintz P. Value of hair analysis in postmortem toxicology. Forensic Sci Int. 2004;142(2):127-34.

9. Villain M, Cirimele V, Kintz P. Hair analysis in toxicology. Clin Chem Lab Med. 2004;42(11):1265-72.

10. Tracqui A, Kintz P, Mangin P. Hair analysis: a worthless tool for therapeutic compliance monitoring. Forensic Sci Int. 1995;70(1): 183-9.

11. Sato H, Uematsu T, Yamada K, Nakashima M. Chlorpromazine in human scalp hair as an index of dosage history: comparison with simultaneously measured haloperidol. Eur J Clin Pharmacol. 1993;44(5):439-44.

12. Cheze M, Villain M, Pepin G. Determination of bromazepam, clonazepam and metabolites after a single intake in urine and hair by LC-MS/MS. Application to forensic cases of drug facilitated crimes. Forensic Sci Int. 2004;145(2-3):123-30.

13. Wang X, Johansen SS, Nielsen MKK, Linnet K. Segmental hair analysis - interpretation of the time of drug intake in two patients undergoing drug treatment. J Forensic Sci. 2019;64(3):950-5.

14. Chatterton C, Kintz P. Hair analysis to demonstrate administration of amitriptyline, temazepam, tramadol and dihydrocodeine to a child in a case of kidnap and false imprisonment. J Forensic Legal Med. 2014;23:26-31.

15. Binz TM, Yegles M, Schneider S, Neels H, Crunelle CL. Time resolved analysis of quetiapine and 7-OH-quetiapine in hair using LC/MS-MS. Forensic Sci Int. 2014;242:200-3.

16. Gunther KN, Johansen SS, Nielsen MKK, Wicktor P, Banner J, Linnet K. Postmortem quetiapine concentrations in hair segments of psychiatric patients - correlation between hair concentration, dose and concentration in blood. Forensic Sci Int. 2018;285:58-64.

17. Günther KN, Johansen SS, Wicktor P, Banner J, Linnet K. Segmental analysis of chlorprothixene and desmethylchlorprothixene in postmortem hair. J Anal Toxicol. 2018;42(9):642-9.

18. Nielsen MK, Johansen SS, Dalsgaard PW, Linnet K. Simultaneous screening and quantification of 52 common pharmaceuticals and drugs of abuse in hair using UPLC-TOF-MS. Forensic Sci Int. 2010;196(1-3):85-92.

19. Schneider S, Sibille E, Yegles M, Neels H, Wennig R, Muhe A. Time resolved analysis of risperidone and 9-hydroxy-risperidone in hair using LC/MS-MS. J Chromatogr B Analyt Technol Biomed Life Sci. 2009;877(24):2589-92.

20. Sticht G, Sevecke K, Kaferstein H, Dopfner M, Rothschild MA. Detection of methylphenidate in the hair of children treated with Ritalin. J Anal Toxicol. 2007;31(9):588-91.

21. Uematsu T, Sato R, Suzuki K, Yamaguchi S, Nakashima M. Human scalp hair as evidence of individual dosage history of haloperidol: method and retrospective study. Eur J Clin Pharmacol. 1989;37(3): 239-44.

22. Ramirez Fernandez MD, Wille SM, Hill V, Samyn N. Determination of antidepressants in hair via UHPLC-MS/MS as a complementary informative tool for clinical and forensic toxicological assessments. Ther Drug Monit. 2016;38(6):751-60.

23. Shen M, Xiang P, Wu H, Shen B, Huang Z. Detection of antidepressant and antipsychotic drugs in human hair. Forensic Sci Int. 2002;126(2):153-61.

24. Wang X, Johansen SS, Nielsen MKK, Linnet K. Hair analysis in toxicological investigation of drug-facilitated crimes in Denmark over a 8-year period. Forensic Sci Int. 2018;285:e1-e12.

25. Methling M, Krumbiegel F, Hartwig S, Parr MK, Tsokos M. Toxicological findings in suicides - frequency of antidepressant 
and antipsychotic substances. Forensic Sci Med Pathol. 2019;15(1):23-30.

26. Kronstrand R, Nystrom I, Josefsson M, Hodgins S. Segmental ion spray LC-MS-MS analysis of benzodiazepines in hair of psychiatric patients. J Anal Toxicol. 2002;26(7):479-84.

27. Mußhoff F, Skopp G, Pragst F, Sachs H, Thieme D. Quality requirements for the analysis of hair samples. Appendix C. In: Guidelines for quality control of forensic-toxicological analyses. English translation, original German version published in Toxichem Krimtech 2009;76(3):209-216.

28. Peters FT, Hartung M, Herbold M, G. Schmitt, Daldrup T, Mußhoff F. Requirements for the validation of analytical methods, Appendix B. In: Guidelines for quality assurance in forensic-toxicological analyses. English translation, original German version published in Toxichem Krimtech. 2009;76(3):185-208.

29. Broecker S, Herre S, Pragst F. General unknown screening in hair by liquid chromatography-hybrid quadrupole time-of-flight mass spectrometry (LC-QTOF-MS). Forensic Sci Int. 2012;218(1):6881.

30. Lohse MJ, Müller-Oerlinghausen B. Psychopharmaka. In: Schwabe U, Paffrath D, editors. Arzneiverordnungs-Report 2016: Aktuelle Daten, Kosten, Trends und Kommentare. Berlin, Heidelberg: Springer Berlin Heidelberg; 2016. p. 663-90.

31. DIN 32645. Chemical analysis-decision limit and determination limit under repeatability conditions-terms, methods, evaluation. Berlin: Beuth; 2008.

32. Kintz P. Segmental hair analysis can demonstrate external contamination in postmortem cases. Forensic Sci Int. 2012;215(1):73-6.

33. Fisichella M, Morini L, Sempio C, Groppi A. Validation of a multianalyte LC-MS/MS method for screening and quantification of 87 psychoactive drugs and their metabolites in hair. Anal Bioanal Chem. 2014;406(14):3497-506.

34. Pragst F, Rothe M, Hunger J, Thor S. Structural and concentration effects on the deposition of tricyclic antidepressants in human hair. Forensic Sci Int. 1997;84(1-3):225-36.

35. Negrusz A, Moore CM, Perry JL. Detection of doxepin and its major metabolite desmethyldoxepin in hair following drug therapy. J Anal Toxicol. 1998;22(6):531-6.

36. Pichini S, Cortes L, Marchei E, Solimini R, Pacifici R, Gomez-Roig $\mathrm{MD}$, et al. Ultra-high-pressure liquid chromatography tandem mass spectrometry determination of antidepressant and anxiolytic drugs in neonatal meconium and maternal hair. J Pharm Biomed Anal. 2016;118:9-16.

37. Wille SM, De Letter EA, Piette MH, Van Overschelde LK, Van Peteghem CH, Lambert WE. Determination of antidepressants in human postmortem blood, brain tissue, and hair using gas chromatography-mass spectrometry. Int J Legal Med. 2009;123(6):451-8.

38. Wang X, Johansen SS, Nielsen MKK, Linnet K. Targeted analysis of 116 drugs in hair by UHPLC-MS/MS and its application to forensic cases. Drug Test Anal. 2017;9(8):1137-51.

39. Papaseit E, Marchei E, Mortali C, Aznar G, Garcia-Algar O, Farre $\mathrm{M}$, et al. Development and validation of a liquid chromatographytandem mass spectrometry assay for hair analysis of atomoxetine and its metabolites: application in clinical practice. Forensic Sci Int. 2012;218(1-3):62-7.
40. Jang M, Kim J, Shin I, Kang S, Choi H, Yang W. Simultaneous determination of methylphenidate and ritalinic acid in hair using LC-MS/MS. Forensic Sci Int. 2019;294:183-8.

41. McClean S, O'Kane EJ, Smyth WF. Electrospray ionisation-mass spectrometric characterisation of selected anti-psychotic drugs and their detection and determination in human hair samples by liquid chromatography-tandem mass spectrometry. J Chromatogr B Biomed Sci Appl. 2000;740(2):141-57.

42. Weinmann W, Muller C, Vogt S, Frei A. LC-MS-MS analysis of the neuroleptics clozapine, flupentixol, haloperidol, penfluridol, thioridazine, and zuclopenthixol in hair obtained from psychiatric patients. J Anal Toxicol. 2002;26(5):303-7.

43. Kronstrand R, Forsman M, Roman M. Quantitative analysis of drugs in hair by UHPLC high resolution mass spectrometry. Forensic Sci Int. 2018;283:9-15.

44. Al JJ. Method development for the detection of basic/weak basic drugs in hair by LCMSMS: comparison between methanolic and alkaline extraction on real samples. Pharmacology \& Pharmacy. 2012;03:263-74.

45. Cirimele V, Kintz P, Gosselin O, Ludes B. Clozapine doseconcentration relationships in plasma, hair and sweat specimens of schizophrenic patients. Forensic Sci Int. 2000;107(1-3):289 300 .

46. Marchei E, Munoz JA, Garcia-Algar O, Pellegrini M, Vall O, Zuccaro P, et al. Development and validation of a liquid chromatography-mass spectrometry assay for hair analysis of methylphenidate. Forensic Sci Int. 2008;176(1):42-6.

47. Kim J, Lee S, In S, Choi H, Chung H. Validation of a simultaneous analytical method for the detection of 27 benzodiazepines and metabolites and zolpidem in hair using LC-MS/MS and its application to human and rat hair. J Chromatogr B Analyt Technol Biomed Life Sci. 2011;879(13-14):878-86.

48. Cirimele V, Kintz P, Ludes B. Screening for forensically relevant benzodiazepines in human hair by gas chromatography-negative ion chemical ionization-mass spectrometry. J Chromatogr B Biomed Sci Appl. 1997;700(1-2):119-29.

49. LeBeau MA, Montgomery MA, Brewer JD. The role of variations in growth rate and sample collection on interpreting results of segmental analyses of hair. Forensic Sci Int. 2011;210(1-3):110-6.

50. Xiang P, Shen M, Drummer OH. Review: drug concentrations in hair and their relevance in drug facilitated crimes. J Forensic Legal Med. 2015;36:126-35.

51. Musshoff F, Thieme D, Schwarz G, Sachs H, Skopp G, Franz T. Determination of hydroxy metabolites of cocaine in hair samples for proof of consumption. Drug Test Anal. 2018;10(4):681-8.

52. Kintz P. Issues about axial diffusion during segmental hair analysis. Ther Drug Monit. 2013;35(3):408-10.

53. Shields LB, Hunsaker DM, Hunsaker JC 3rd, Ward MK. Toxicologic findings in suicide: a 10-year retrospective review of Kentucky medical examiner cases. Am J Forensic Med Pathol. 2006;27(2):106-12.

Publisher's Note Springer Nature remains neutral with regard to jurisdictional claims in published maps and institutional affiliations. 